Revista Brasileira do Esporte Coletivo - v. 4. n. 1. 2020.

Artigo Original

\title{
CARACTERIZAÇÃO DO ATAQUE EM SISTEMA COM A UTILIZAÇÃO DA “BALIZA DESERTA" NO HANDEBOL FEMININO
}

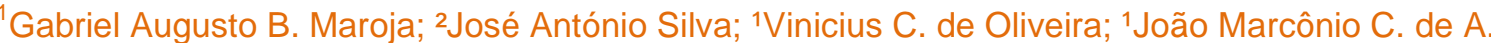

Filho;

\section{RESUMO}

Introdução: As últimas alterações nas regras do Handebol têm tido repercussões decisivas no comportamento tático das equipes na competição. A possibilidade de uma equipe jogar sem goleiro, introduzida nos jogos Olímpicos de 2016, levou equipes a alterar suas estratégias ofensivas fundamentalmente nas situações de igualdade e inferioridade numérica. Objetivo: $O$ presente estudo teve como principal objetivo caracterizar as situações que ocorreram na fase de ataque em sistema, nas quais as equipes optam por substituir o goleiro por um jogador de campo, para atacar em superioridade numérica, ou em igualdade numérica. Metódo: A amostra utilizada foi constituída por (16) jogos da fase de play-off (a partir das oitavas de final) do Campeonato do Mundo de Seniores Feminino 2017. Para efetuar o registro foi utilizado o instrumento de observação ad-hoc. Desse registro, resultou um total de 3107 sequências ofensivas e 1760 ataques finalizados. Resultados e Discussão: Dos resultados obtidos destacam-se: (I) a eficácia das equipes numa situação de ataque com a baliza deserta 6 X6 é maior do que a obtida quando atacam 7 X6, (vitoriosas: $48.5 \%$ vs $47.6 \%$; derrotadas - $40.7 \%$ vs $33.3 \%$ ); (II) quando as equipes estão em inferioridade numérica com menos uma jogadora, o ataque com "baliza deserta" (6X6) revela-se mais eficaz do que 0 ataque em inferioridade numérica 5 X6 (vitoriosas: $45.5 \%$ vs $32.4 \%$; derrotadas - $50 \%$ vs $24 \%$ ).

Palavras-chave: Esporte, Futebol, Iniciação.

${ }^{1}$ Centro Universitário de João Pessoa, João Pessoa, Paraíba, Brasil., ${ }^{2}$ Faculdade de Desporto da Universidade do Porto, Portugal.

Endereço: Praceta Trindade Coelho, no 70 - Águas Santas - Maia - Portugal

E-mail: gabrielbmaroja@gmail.com; jasdps@fade.up.pt; v9pb@hotmail.com; marconiohand@hotmail.com

\section{CHARACTERIZATION OF THE ATTACK IN SYSTEM WITH US OF "EMPTY GOAL" IN FEMALE HANDBALL}

\section{ABSTRACT}

Introduction: The latest changes in the handball rules have had decisive repercussions on the team's tactical behavior in the competition. The possibility for a team to play without a goalkeeper, introduced in the 2016 Olympic Games, has led teams to change their offensive strategy fundamentally in situations of equality and in situations of numerical inferiority. Objective: The aim of the study was to characterize the attack in the system phase situations, where teams choose to substitute the goalkeeper for a field player, to attack in numerical superiority, or numerical equality. Method: Data from (16) games of the play-off phase (from the quarter final) of the Senior Feminine World Cup of 2017, were analyzed, through the ad-hoc observation. From the registration resulted a total of 3107 offensive sequences and 1760 finalized attacks. Results and Discussion: The results highlight that: (I) the efficacy of the teams in an $6 \times 6$ attack situation, is higher than the one obtained when the team uses an $7 \times 6$ attack, with the goal deserted, (victorious: $48.5 \%$ vs $47.6 \%$ defeated $-40.7 \%$ vs $33.3 \%$ ); (II) when the teams are at a numerical disadvantage with one player less, the attack with "deserted goal" (6x6) appears to be more effective than an attack at a numerical disadvantage $5 \times 6$ (victorious: $45.5 \%$ vs $32.4 \%$; defeated $-50 \%$ vs $24 \%$ ). Conclusion: It was concluded that the majority of attacks with a deserted goal occurred in situations of absolute numerical equality, or in situations of absolute numerical inferiority of a player, being this strategy more effective for both teams during the absolute numerical inferiority.

Key words: Deserted Goal, Goal keeper, Numerical Equality, Numerical Advantage. 
BALIZA DESERTA

' Centro Universitário de João Pessoa, João Pessoa, Paraíba, Brasil. ${ }^{2}$ Faculdade de Desporto da Universidade do Porto, Portugal.

\section{E-mail: gabrielbmaroja@gmail.com; jasdps@fade.up.pt; v9pb@hotmail.com; marconiohand@hotmail.com}

\section{INTRODUÇÃO}

A análise do jogo é um dos recursos essenciais nos Jogos Desportivos Coletivos, determinante para a avaliação da performance das equipes e jogadores, contribuindo para a evolução das modalidades, esse trabalho se iniciou nos anos 30 (GARGANTA, 2001; SILVA, GARGANTA, JANEIRA, 2013). Atualmente, 0 avanço tecnológico e a diversidade de metodologias para a realização da análise do jogo tornam as conclusões daí decorrentes cada vez mais fidedignas, proporcionando o aumento do conhecimento por parte de treinadores e atletas (GARGANTA, 2001). Tal análise tem por finalidade encontrar os principais fatores que influenciam 0 desempenho dos atletas, quantificando suas ações individuais e coletivas, incluindo os aspectos técnico, tático, físico e psicológico (MENEZES, REIS, 2010; SILVA, GARGANTA, JANEIRA, 2013).

Para além destes objetivos, a análise do jogo nos jogos desportivos coletivos pretende, em muitos casos, descrever e analisar as principais ações táticas que diferenciam as equipes vitoriosas das derrotadas, tarefas determinantes para a construção de um modelo de jogo e treinamento eficientes (GARGANTA, 2007; FERRARI, SARMENTO, VAZ, 2019; SILVA, GARGANTA, JANEIRA, 2013). A análise dos comportamentos táticos das equipes e a compreensão dos fatores que discriminam as equipes de maior sucesso das restantes, tem sido uma temática presente em muitos trabalhos de investigação (MIRANDA, 2016; PRUDENTE et al., 2017; TELLES, VOLOSSOVITCH, 2015).

Neste âmbito, o estudo das repercussões para o jogo decorrentes de novas abordagens do ponto de vista tático, bem como das alterações regulamentares verificadas, assume uma grande importância. De fato, essas alterações proporcionam momentos em que a dinâmica do jogo se altera, pelo que urge perceber a forma que ela é afetada e ainda os efeitos concretos dessa ação.

No que diz respeito ao handebol, os primeiros trabalhos neste âmbito são conhecidos a partir dos anos 70 (PRUDENTE, 2006). Atualmente, são conhecidos inúmeros trabalhos na modalidade que permitem observar, descrever e monitorar as principais mudanças que se verificam nas componentes físicas, psicológicas, técnica e tática (CLEMENTE et al., 2019; PIETRO, GÓMEZ, SAMPAIO, 2015; VOLOSSOVITCH, 2016).

Para Ferrari, Sarmento e Vaz (2019) e Okazaki et al., (2012) a ciência e a tecnologia contribuem para a análise desportiva, oferecendo aos treinadores a possibilidade de utilizar métodos de treino mais próximos da realidade do jogo. Para além de aumentar o conhecimento prévio dos aspectos tático, técnico e físico dos seus jogadores, fundamentais para o trabalho a realizar em toda a temporada, a recolha de informações referente aos adversários pode gerar uma melhor resposta na partida a favor da sua equipe.

De acordo com Silva (2008) a análise do desempenho no handebol tem-se concentrado cada vez mais em ações que decorrem no jogo, com uma ênfase maior no que diz respeito à tática que as equipes utilizam durante a partida. Ao longo dos 60 minutos de uma partida de handebol (não considerando os casos em que há prorrogações) as equipes adotam diferentes comportamentos táticos e sistemas de jogo, para obterem o sucesso quer na defesa, quer no ataque.

Para que os resultados decorrentes da análise efetuada sejam relevantes para a modalidade, os investigadores recorrem a diversas metodologias e ferramentas estatísticas que permitem torná-la mais rigorosa e consistente (PRUDENTE, 2006; SILVA, 2008; MENEZES, REIS, 2010). Neste âmbito, 0 recurso à Metodologia Observacional, é frequente já que oferece ao investigador ou treinador a oportunidade de 
analisar as sequências em contexto real e eventualmente detectar, situações imperceptíveis no decurso do jogo (ANGUERA, MENDO, 2013; SILVA, GARGANTA, JANEIRA, 2013).

No handebol atual, é frequente que na fase de ataque em sistema as equipes abdiquem da presença em campo do seu goleiro deixando a "baliza deserta". Até 2016 esta situação implicava que o jogador de campo que substituía o goleiro, estivesse identificado com uma camisa diferente dos restantes companheiros de equipe, já que era obrigatória a presença em campo de um jogador com a função de goleiro (Regra 4.7). Esta situação verificava-se principalmente nas situações de desigualdade numérica absoluta, possibilitando uma opção tática ofensiva para as equipes e assim minimizar o fato de estar com menos jogadores em campo, já que tinham sido alvo de suspensões ou desqualificações (AGULLÓ-ESPINA, PÉREZTURPIN, CEJUELA-ANTA, 2012; GARCÍA, 2015; SECO, 2015). No entanto, várias equipes foram adotando 0 mesmo comportamento mesmo estando em igualdade numérica absoluta, para que possam jogar com mais um jogador de ataque (7x6).

Em Agosto de 2016 foi introduzida uma alteração ao regulamento que permite a utilização apenas de jogadores de campo num determinado momento, não sendo como até aí, obrigatória a presença de um elemento com as funções de goleiro. Esta alteração entrou em vigor nas olimpíadas do Rio de Janeiro, proporcionando um aumento da frequência com que é utilizada a estratégia atrás referida, já que facilita a substituição do goleiro por qualquer jogador de campo, mudando a estratégia ofensiva da equipe (SILVA, LEAL, 2017).

Como já foi referida, essa estratégia começou a ser utilizada de forma mais frequente nos últimos anos, pelo que o número de estudos realizados com essa temática é escasso. $\mathrm{Na}$ pesquisa realizada apenas foi possível identificar os trabalhos de Antón (2010), Musa et al., (2017), Beiztegui-Casado, Oliver-Coronado e Sosa-González (2019) (antes da alteração da regra) e depois da mudança, três trabalhos; Leal e Silva (2017), Ferrari e Vaz (2018), Krahenbühl et al., (2019). Antón (2010) observou esta abordagem tática antes da modificação na regra durante o Campeonato Europeu na Áustria, constatando que apenas três seleções utilizaram esta estratégia: Espanha, Áustria e Croácia. $O$ estudo não possui dados estatísticos e o autor acaba por sugerir mais estudos científicos que apresentem dados estatísticos detalhados e confiáveis para futuras discussões acerca deste tema. Estas situações ocorreram quando as equipes permaneciam em inferioridade numérica absoluta e tentavam um ataque em sistema com igualdade $(6 \times 6)$, sendo de realçar que em todas as situações analisadas nenhuma equipe conseguiu marcar gol.

De acordo com Antón (2010) existem vantagens e desvantagens que as equipes podem levar quando adotam esta estratégia no ataque.

Vantagens:

1- Atenuar o efeito de estar em inferioridade numérica absoluta, atacando em igualdade (6x6);

2- Reivindicar a atenção do defensor para fora, podendo teoricamente aumentar o espaço livre na zona oposta e jogar $2 \times 2$ e até $3 \times 3$;

3- $O$ autor destaca que, nesta situação é favorável utilizar jogadores mais experientes e de confiança, estes provavelmente tomarão decisões pertinentes a esta situação frente aos adversários.

Desvantagens:

1- Deixar a baliza deserta e sem proteção;

2- Este "sexto jogador" em algumas ocasiões é mais figurante que real, não oferecendo perigo para a defesa, não atacando a baliza e facilitando o trabalho adversário.

3- Devido às circunstâncias especiais desta situação, o tempo de posse de bola da equipe atacante se reduz, pois se inicia o ataque de forma muito passiva, e para evitar o aviso de iminência de jogo passivo pelos árbitros, os jogadores tendem a acelerar o jogo, não selecionando bem as opções de arremesso à baliza.

4- Em caso improvável de gol nestas condições é bastante possível que a equipe adversária realize de forma imediata outro gol, através do "contra-ataque" (reposição rápida com um tiro de saída, após sofrer o gol).

No estudo elaborado por Musa et al., (2017), no Campeonato Europeu de Handebol Masculino Sênior em 2016 (antes da alteração na regra) foram observadas 201 sequências em que as equipes utilizavam o guarda redes no ataque, sendo que $91.5 \%$ dos casos foram quando a equipe encontrava-se em inferioridade numérica absoluta e apenas $6.5 \%$ quando estava em igualdade numérica absoluta (7x7). Tendo em atenção o tempo de jogo, verifica-se uma maior utilização nos últimos 10 minutos finais da partida (23.9\%).

Em estudo recente realizado por Silva \& Leal (2017), verificou-se que as equipes derrotadas utilizam 0 ataque com o goleiro 


\section{BALIZA DESERTA}

cinco vezes mais que as vitoriosas. Em 85\% das ocasiões verificadas ele é utilizado quando estão em desvantagem no marcador para ambas as equipes. As equipes vitoriosas obtiveram melhor eficácia de ataque nas duas situações analisadas, inferioridade numérica absoluta (6x6 com a substituição do goleiro) e igualdade numérica absoluta (7x7).

Ferrari \& Vaz (2018) compararam no seu estudo a utilização do ataque em sistema com a baliza deserta na Champions League antes e depois da atualização da regra, verificou-se diferenças estatisticamente significativas no número de ações entre as duas épocas, 54 na temporada 15/16 e 103 na 16/17. Os autores chegaram a conclusão que essa atualização influenciou a forma de jogar das equipes, apresentando um novo modelo de jogo no ataque em sistemas.

Tendo em consideração o que atrás foi exposto, os principais objetivos do presente estudo são (I) caracterizar os ataques e calcular a eficácia obtida, realizados na fase de ataque em sistemas, nas quais as equipes optam por substituir o goleiro por um jogador de campo, para atacar em superioridade numérica ou em igualdade numérica e (II) identificar e caracterizar eventuais diferenças entre equipes vitoriosas e derrotadas. Para além das razões apontadas, o fato do presente trabalho se realizar com os jogos do primeiro Campeonato do Mundo Feminino Sênior efetuado após a alteração ao regulamento, reforça a importância desta investigação.

\section{MÉTODO}

Para a realização do presente trabalho foram cumpridas as fases do processo de investigação a partir da Metodologia Observacional, propostos para o estudo do fenômeno desportivo por Anguera Argilaga et al., (2000). A amostra foi de 16 jogos da fase de play-off (a partir das oitavas de final) do Campeonato do Mundo Sênior Feminino 2017, dos quais foram retiradas 3107 sequências ofensivas, através do instrumento de observação ad-hoc adaptado de Silva (2008).
Análise descritiva dos dados foi efetuada com - recurso a medidas de frequência e porcentagem. Com 0 intuito de encontrar diferenças entre equipes vitoriosas e derrotadas, foram consideradas medidas de frequência (absoluta e relativa), bem como o cálculo de porcentagens e índices de eficácia, realizados no Microsoft Excel 2016.

\section{DISCUSSÃO}

Para a realização do presente trabalho foram cumpridas as fases do processo de investigação a partir da Metodologia Observacional, propostos para o estudo do fenômeno desportivo por Anguera Argilaga et al., (2000). A amostra foi de 16 jogos da fase de play-off (a partir das oitavas de final) do Campeonato do Mundo Sênior Feminino 2017, dos quais foram retiradas 3107 sequências ofensivas, através do instrumento de observação ad-hoc adaptado de Silva (2008). Análise descritiva dos dados foi efetuada com o recurso a medidas de frequência e porcentagem. Com o intuito de encontrar diferenças entre equipes vitoriosas e derrotadas, foram consideradas medidas de frequência (absoluta e relativa), bem como o cálculo de porcentagens e índices de eficácia, realizados no Microsoft Excel 2016.

\section{Apresentação e discussão dos resultados \\ Neste ponto do trabalho são} apresentados os resultados obtidos a partir da análise dos dados. Num primeiro momento, atendendo à influência que a relação numérica absoluta tem na definição da estratégia das equipes e no resultado do confronto (ANTÓN, 2010; FERRARI, VAZ, 2018; MUSA et al., 2017; SILVA, LEAL, 2017), importa perceber de que forma essa variável condiciona a adoção do "Ataque com baliza deserta".

$\mathrm{Na}$ Tabela 1, são apresentados os valores relativos aos ataques finalizados com recurso ao "Ataque com baliza deserta", em função da relação numérica verificada em cada momento 


\section{BALIZA DESERTA}

Tabela 1. Valores absolutos e porcentuais dos ataques finalizados em função da relação numérica verificada.

\begin{tabular}{ccccc}
\hline Variáveis & Total & Vitoriosas & Derrotadas & \% TOTAL \\
\hline $\mathbf{7 X 7}$ & 72 & 21 & 51 & 41.9 \\
Inferioridade 1 jogadora & 81 & 33 & 48 & 47.1 \\
Superioridade 1 jogadora & 3 & 1 & 2 & 1.7 \\
Inferioridade 2 jogadoras & 2 & 2 & 0 & 1.2 \\
$6 \times 6$ & 14 & 7 & 7 & 8.1 \\
\hline Total & 172 & 64 & 108 & 100 \\
\hline
\end{tabular}

De acordo com os números apresentados na Tabela 1, a maior porcentagem de ataques finalizados com a "baliza deserta" (47.1\%), aconteceu quando as equipes estavam em inferioridade de 1 jogadora após exclusão por dois minutos ou desqualificação, proporcionando um ataque em igualdade numérica $(6 \times 6)$. A segunda maior porcentagem de utilização do ataque com baliza deserta $(41.9 \%)$ verifica-se quando as equipes se encontram completas (7x7), pelo que a substituição da goleira por uma jogadora de campo, proporciona situações de ataque em superioridade numérica $7 \times 6$.

Da análise da Tabela 1 conclui-se que as situações em que mais vezes se utiliza o "Ataque com baliza deserta", ocorrem quando as equipes se encontram em igualdade numérica absoluta $7 \times 7$, ou em inferioridade numérica absoluta com menos uma jogadora, totalizando $89 \%$ dos ataques finalizados com recurso a esta estratégia.

Assim sendo, os próximos pontos do trabalho vão analisar de forma mais detalhada os ataques que ocorrem com as situações de relação numérica referidas, sendo as restantes, (I) superioridade numérica absoluta de uma jogadora, (II) inferioridade numérica absoluta de duas jogadoras, (III) ambas as equipes com exclusão (6X6), alvo de uma análise mais resumida no final.

\section{Igualdade numérica absoluta 7X7}

Nas situações de igualdade numérica absoluta $7 \times 7$ analisaram-se no total 1401 ataques, sendo 700 para as equipes vitoriosas, em que 536 foram finalizadas através de ataque em sistema ou livres de 9 metros e 164 por meio de transições. No que diz respeito às equipes derrotadas ocorreram 701 ataques, sendo 528 finalizados através de ataques posicionados em sistema ou tiros livres de 9 metros e 173 utilizando as transições.

$\mathrm{Na}$ Figura 1 são apresentados os valores porcentuais dos ataques finalizados pelas equipes vitoriosas e derrotadas durante 0 ataque em sistema, livres de 9 metros e transições. Em seguida, com base nos valores obtidos no ataque posicionados em sistema ou tiro livres de 9 metros, apresentam-se as porcentagens de ataques em sistema finalizados quando as equipes se encontram (I) jogando sem a baliza deserta (ataque 6X6) e (II) com a baliza deserta, assumindo o ataque em superioridade $(7 \times 6)$. 
BALIZA DESERTA

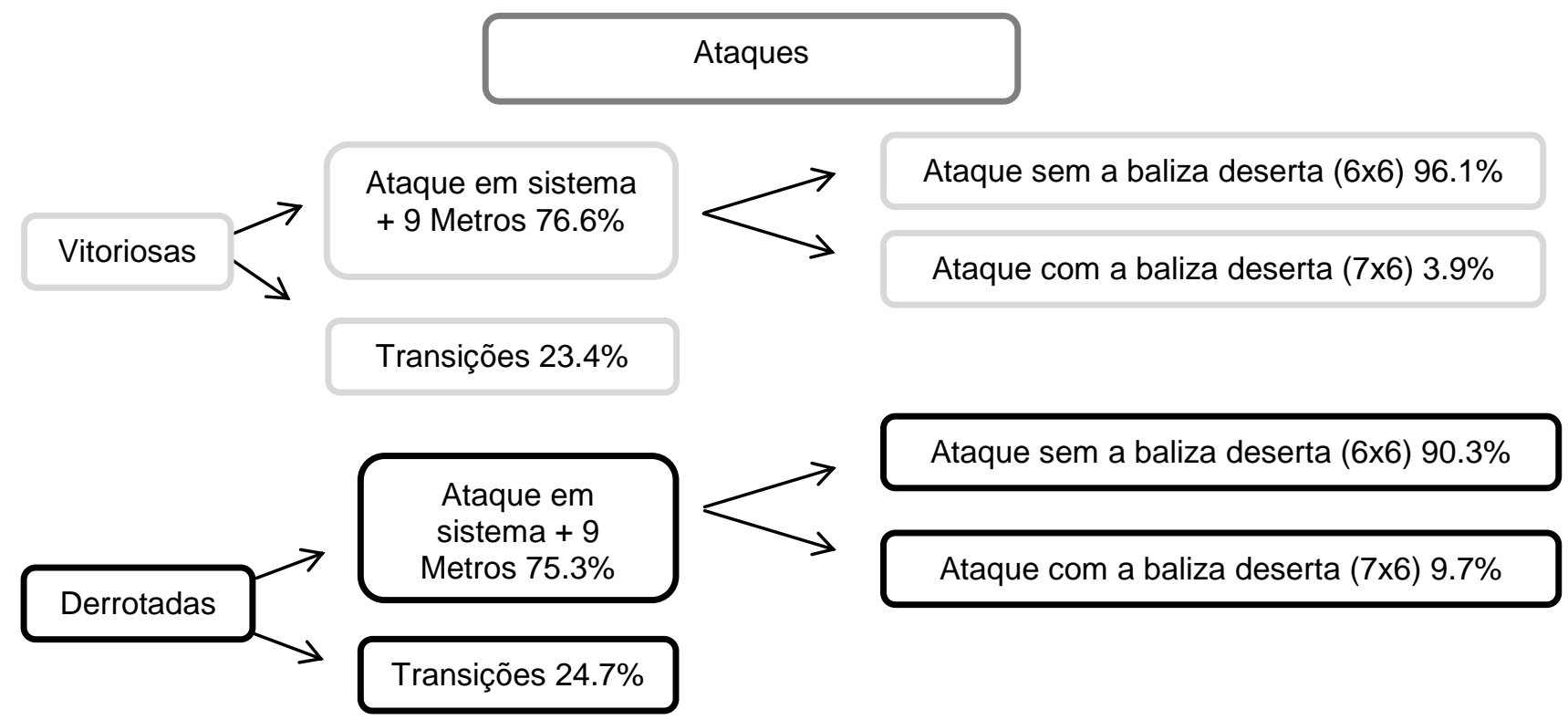

Figura 1. Valores porcentuais relativos à finalização dos ataques, atendendo à fase do jogo e estratégia utilizada.

Analisando os dados da Figura 1 verifica-se uma porcentagem de ataques finalizados a partir do ataque em sistema ou livre de 9 metros muito semelhante entre as equipes vitoriosas $(76.6 \%)$ e as derrotadas (75.3\%).

Constata-se ainda nos resultados apresentados na Figura 1, que há uma diferença notória na utilização do ataque sem baliza deserta, quando comparados com aqueles que se realizam com baliza deserta para os dois grupos de equipes. De fato, quer as equipes Vitoriosas, quer as Derrotadas utilizam maioritariamente o ataque em sistema sem a baliza deserta $(96.1 \%$ e $90.3 \%$ respectivamente). Quando considerados os ataques em que ocorre a troca da goleira por uma jogadora de campo deixando a baliza deserta, verifica-se que as seleções derrotadas finalizam mais ataques nesta situação do que as vitoriosas $(9.7 \%$ Derrotadas vs 3.9\% Vitoriosas).

A Tabela 2 apresenta a porcentagem de ataques finalizados com recurso ao $7 \times 6$, o que implica a substituição da goleira por uma jogadora de campo, em função do resultado verificado em cada momento das partidas.

Tabela 2. Valores porcentuais de ataques finalizados com "baliza deserta" em função do resultado verificado no momento.

\begin{tabular}{lllllc}
\hline Equipes & $\begin{array}{l}\text { Desvantagem } \\
(\%)\end{array}$ & no marcador & Empate (\%) & $\begin{array}{l}\text { Vantagem no marcador } \\
(\%)\end{array}$ & $\%$ Total \\
\hline Vitoriosas & 28.6 & 23.8 & 47.6 & 100 \\
Derrotadas & 96.2 & 3.8 & 0 & 100 \\
\hline
\end{tabular}

Segundo os dados da Tabela 2 para as equipes vitoriosas $47.6 \%$ das situações ocorrem quando estão na frente do marcador e $52.4 \%$ quando o jogo está empatado ou estão perdendo, enquanto para as equipes derrotadas $96.2 \%$ das situações ocorrem quando estão perdendo. Nota-se quando as equipes derrotadas estão na frente do placar não optam por essa estratégia, o que pressupõe que para estas equipes essa estratégia parece ser utilizada principalmente como uma tentativa de reverter o placar, ou não permitir um aumento na diferença do marcador.

\section{Inferioridade numérica absoluta com menos uma jogadora \\ Nas situações de inferioridade} numérica absoluta com menos uma jogadora observou-se 144 ataques, sendo 70 para as 


\section{BALIZA DESERTA}

equipes vitoriosas, nas quais 67 foram finalizadas através de ataque em sistema ou livres de 9 metros e três por meio de transições. As equipes derrotadas finalizaram 74 ataques nesta situação, sendo os ataques posicionados em sistema ou tiro livres de 9 metros 73 e apenas um em transição.

$\mathrm{Na}$ Figura 2 são apresentados os valores porcentuais relativos à finalização dos ataques para as equipes vitoriosas e derrotadas em situação de inferioridade numérica absoluta (menos uma jogadora). Apresentam-se ainda os valores porcentuais de ataque posicionado em sistema ou tiros livres de nove metros, que ocorrem numa situação de $5 \times 6$, bem como daqueles em que se verifica a substituição da goleira por uma jogadora de campo ocasionando um ataque $6 \times 6$.

\section{Ataques}

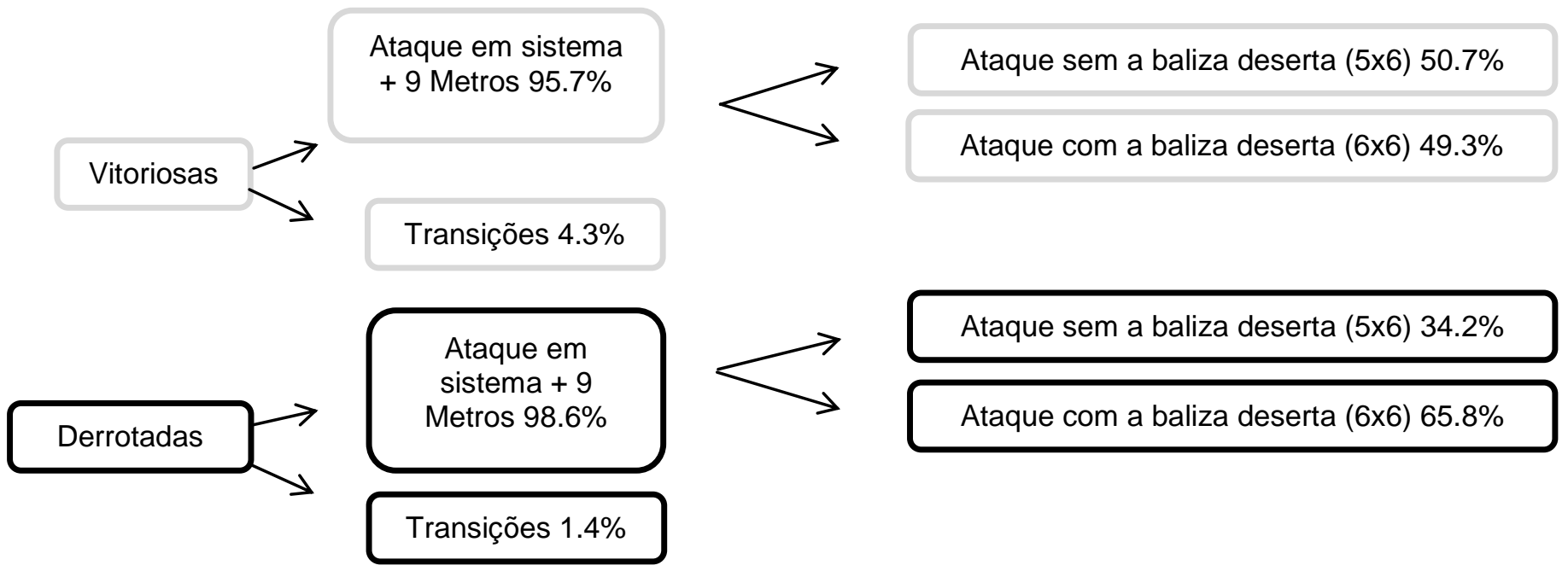

Figura 2. Valores porcentuais relativos à finalização dos ataques, atendendo à fase do jogo e estratégia utilizada.

Analisando os dados da Figura 2 verifica-se uma frequência de ataques em sistema praticamente idêntica entre as equipes vitoriosas (95.7\%) e as derrotadas (98.6\%), sendo realçado que os ataques em transição são utilizados numa porcentagem reduzida.

Ao contrário do que sucede nas situações de igualdade numérica absoluta, nos ataques finalizados em inferioridade numérica (menos uma jogadora) verifica-se uma diferença perceptível no comportamento de equipes vitoriosas e derrotadas. De fato, as equipes derrotadas utilizam mais vezes o ataque com baliza deserta para finalizar os ataques (65.8\%) do que as equipes vitoriosas (49.3\%) corroborando os estudos de Garcia (2010) e Musa et al., (2017), que afirmam em seus estudos que essa situação tática prevalece durante a inferioridade numérica das equipes.

$\mathrm{Na}$ Tabela 3 apresentam-se os resultados da análise dos ataques realizados com a baliza deserta, em função do resultado que se verifica em cada momento do jogo. 
BALIZA DESERTA

Tabela 3. Valores porcentuais de ataques finalizados com "baliza deserta" em função do resultado verificado no momento.

\begin{tabular}{llllll}
\hline Equipes & $\begin{array}{l}\text { Desvantagem } \\
(\%)\end{array}$ & no marcador & Empate (\%) & $\begin{array}{l}\text { Vantagem } \\
(\%)\end{array}$ & no marcador \\
\hline Vitoriosas & 9.1 & 12.1 & 78.8 & 100 \\
Derrotadas & 68.8 & 8.3 & 22.9 & 100 \\
\hline
\end{tabular}

De acordo com a Tabela 3 observa-se para as equipes vitoriosas $78.8 \%$ das situações ocorrem quando estão na frente do placar, enquanto para as equipes derrotadas $68.8 \%$ ocorrem quando estão em desvantagem. Os resultados obtidos confirmam o que se verifica para os ataques que ocorrem em igualdade numérica absoluta (Tabela 2), pelo que é possível identificar uma tendência no comportamento das equipes. De fato, observa-se que as equipes vitoriosas utilizam mais vezes 0 ataque com baliza deserta quando estão na frente do marcador, podendo pressupor-se que essa estratégia seja utilizada para aumentar a vantagem no marcador. Por sua vez, as equipes derrotadas fazem uma utilização preferencial dessa estratégia quando se encontram em desvantagem, podendo deduzir-se que procuram reverter o placar.

\section{Eficácia de ataque obtida nas diferentes situações}

$\mathrm{Na}$ Figura 3 são apresentados os valores de eficácia (em porcentagem) do ataque em sistema obtidos pelas equipes vitoriosas e derrotadas, nas situações de igualdade numérica absoluta (7x7) e inferioridade numérica absoluta (menos uma jogadora).

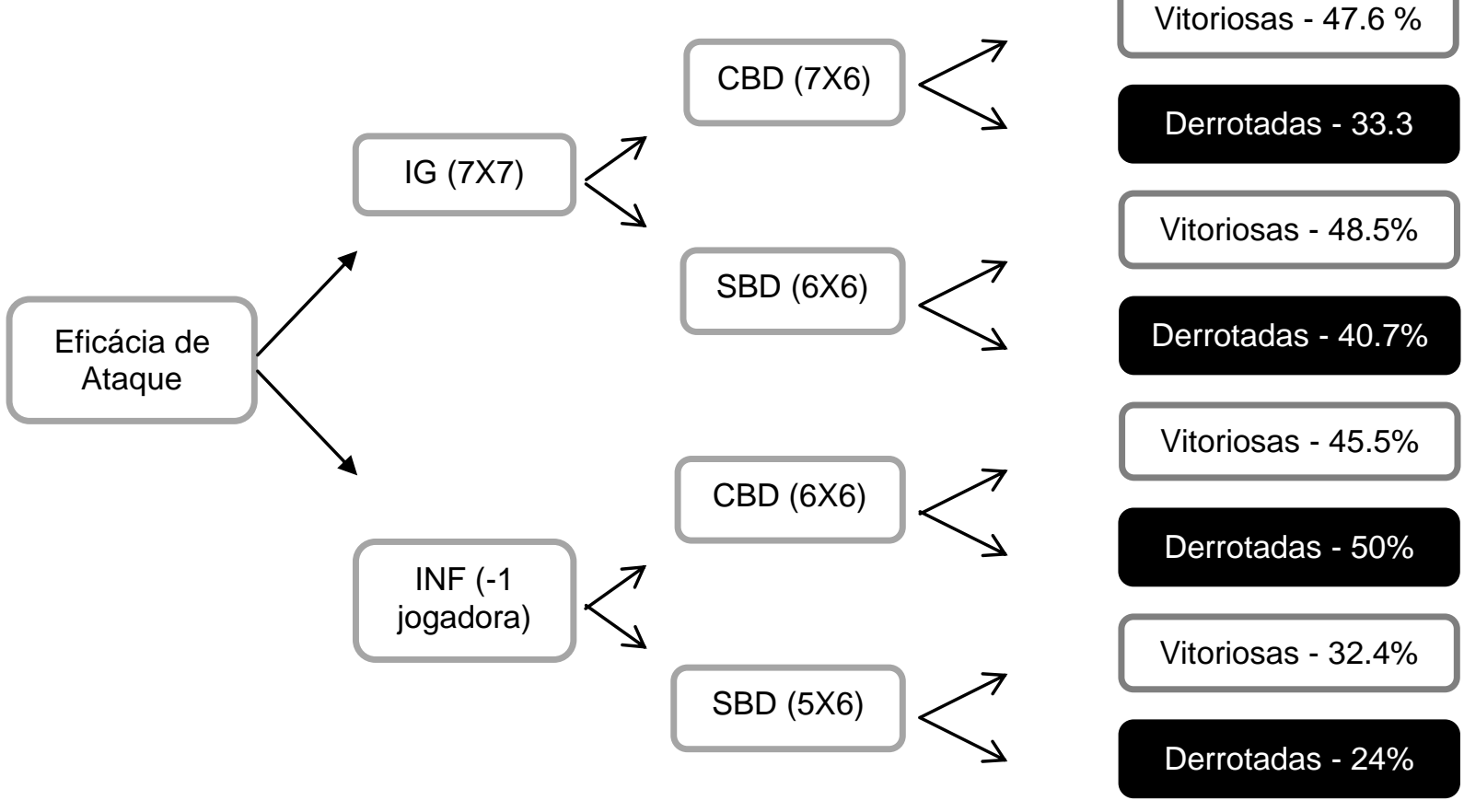

Figura 3. Valores porcentuais da eficácia das equipes vitoriosas e derrotadas durante o "Ataque em sistema" sem a baliza deserta (SBD) e com a baliza deserta (CBD). IG: Igualdade Numérica. INF: Inferioridade Numérica.

$\mathrm{Na}$ análise dos resultados apresentados na Figura 3, constata-se que a eficácia de ataque das equipes vitoriosas e derrotadas, quando em igualdade numérica absoluta, é maior nas situações de ataque sem "baliza deserta" do que quando utilizam essa estratégia (Vitoriosas $48.5 \%$ vs $47.6 \%$ /
Derrotadas $40.7 \%$ vs $33.3 \%$ ). Estes valores colocam em causa a utilização dessa estratégia, já que os dois grupos de equipes têm um decréscimo de eficácia de ataque. Esta situação é mais penalizadora para as equipes derrotadas (a eficácia diminui 7.4\%) do que para as equipes vitoriosas (diminui 


\section{BALIZA DESERTA}

apenas 1\%). Este fato assume ainda mais relevância se tivermos em conta a situação, relativamente ao resultado, em que as equipes derrotadas utilizam 0 ataque com "baliza deserta". Como é possível observar na Tabela 2 , as equipes derrotadas utilizam essa estratégia quase exclusivamente quando se encontram em desvantagem no marcador (96.2\%), depreende-se, com o intuito de recuperar o resultado, pelo que a diminuição de eficácia constatada, acaba por comprometer esse objetivo.

Já no que diz respeito à eficácia de ataque com a baliza deserta, nas situações de inferioridade numérica de uma jogadora, em que as equipes optam por substituir a goleira por uma jogadora de campo, destacam-se os $45.5 \%$ de eficácia obtido pelas equipes vitoriosas nesta situação (ataque 6x6), quando comparado com os $32.1 \%$ obtidos quando optam por jogar 5X6 (Figura 3). Do mesmo modo, também as equipes derrotadas apresentam diferenças relevantes nas eficácias de ataque obtidas quando da utilização das duas estratégias (eficácia de ataque com "baliza deserta" - 50\%; eficácia de ataque sem "baliza deserta" - 24\%).

Os resultados obtidos parecem justificar a adoção do ataque com "baliza deserta" nas situações de inferioridade numérica absoluta, já que se verifica um aumento da eficácia obtida pelos dois grupos de equipes, ao contrário do que foi concluído nos estudos de Antón (2010), no qual o autor constatou que a utilização desta estratégia não se justificava e de Krahenbühl et al., (2019) em que não foram encontradas diferenças estatisticamente significativas quando se compara o ataque com e sem substituição do goleiro. Por outro lado, os resultados do presente trabalho parecem confirmar as conclusões de Beiztegui-Casado, OliverCoronado e Sosa-González (2019) num estudo realizado com Campeonato do Mundo de 2015 feminino sênior (antes da atualização da regra), em que os autores constataram a

\section{CONCLUSÃO}

Como já referido, a utilização de um elemento extra no ataque é uma estratégia utilizada há vários anos no Handebol. A partir dos resultados obtidos importa realçar um conjunto de conclusões que podem ter repercussão na condução do processo de treino e da competição: (I) A maioria dos ataques com baliza deserta ocorre em situações de igualdade numérica absoluta $7 X 7$, ou em situações de inferioridade numérica absoluta de uma jogadora; (II) As equipes vitoriosas utilizam mais esta estratégia existência de diferenças estatisticamente significativas nas situações de inferioridade numérica (eficácia de $45.45 \%$ com "baliza deserta" vs $33.76 \%$ sem "baliza deserta").

Pode-se deduzir que nos últimos anos se verificou uma melhoria da utilização dessa estratégia já que os resultados agora obtidos, confirmam que jogar com baliza deserta (6X6 no ataque em sistema) é uma alternativa eficiente para atacar enquanto se cumpre o tempo decorrente da aplicação de sanções disciplinares, ao contrário do que estudos anteriores indicam.

No decurso deste estudo, foram ainda identificados ataques com "baliza deserta" noutras situações de relação numérica absoluta, para além das que foram analisadas nos pontos anteriores. De fato, também se verificaram ataques com baliza deserta quando as equipes se encontravam (I) em igualdade numérica absoluta 6X6 (ambas com uma jogadora suspensa), (II) uma equipe estava em superioridade numérica absoluta com mais duas jogadoras (7X5) e (III) uma equipe estava em inferioridade numérica absoluta com menos duas jogadoras (5X7).

No primeiro caso, as equipes retiravam a sua goleira, assumindo 0 ataque em $6 \times 5$, constituindo os ataques realizados nesta situação, $8.1 \%$ do total de ataques realizados com baliza deserta. No segundo caso, apenas $1.7 \%$ dos ataques foram realizados, com 7 jogadoras de campo. Por último, nas situações em que as equipes têm apenas 5 jogadoras em campo, também ocorreram ataques sem baliza deserta (5X6), que constituíram $1.2 \%$ do total de ataques com a utilização desta estratégia. Os ataques realizados nestas três situações de relação numérica absoluta não foram analisados de forma exaustiva por apresentarem uma frequência de utilização reduzida. No entanto, entende-se como relevante fazer referência ao fato da utilização desta estratégia nestas situações.

nas situações de vantagem no marcador, enquanto as equipes derrotadas o fazem quase exclusivamente quando se encontram em desvantagem; (III) Nas situações de igualdade numérica absoluta $7 \times 7$, a eficácia de ataque em sistema de equipes vitoriosas e derrotadas reduz-se quando se utiliza o ataque com baliza deserta, quando comparada com a que é obtida no ataque sem substituição da goleira; (IV) Quando existe inferioridade numérica absoluta de uma jogadora, constatase um aumento da eficácia de ataque nas 
situações em que as equipes utilizam o ataque com baliza deserta, em comparação com a eficácia obtida nos ataques que são efetuados em inferioridade numérica, comprovando a utilidade desta estratégia nestes casos.

\section{REFERÊNCIAS}

ANTÓN GARCÍA, J. L. Uso del "Portero Falso" en inferioridad numérica atacante: ¿Nueva aportación táctico-estratégica?. E-balonmano. com: Revista de Ciências Del Desporte, v. 6, n. 1, p. 3-27, 2010.

ANGUERA, M. T. et al. La metodología observacional en el deporte: conceptos básicos. Lecturas: EF y Deportes. Revista Digital, v. 24, n. 5, p. 63-82, 2000.

ANGUERA, M. T.; MENDO, A. H. La metodología observacional en el ámbito del deporte. Ebalonmano.com: Revista de Ciencias del Deporte, v.9, n. 3, p. 135-160, 2013.

AGULLÓ, J. J. E.; TURPIN, J. A. P.; ANTA, R. C. Evolución histórica y táctica de los sistemas de juego defensivos en balonmano en situaciones de desigualdad numérica. E-balonmano. com: Revista de Ciencias del Deporte, v. 8, n. 2, p. 93-104, 2012.

BEIZTEGUI-CASADO, C.; OLIVER-CORONADO, J.; SOSA-GONZÁLEZ, P. I. Portero-jugador en situaciones de inferioridad numérica ofensiva en balonmano: ¿penalización o ventaja?. Revista Internacional de Medicina y Ciencias de la Actividad Física y del Deporte, v. 19, n.74, 2019.

CLEMENTE, F. M. et al. Variations of perceived load and well-being between normal and congested weeks in elite case study handball team. Research in Sports Medicine, v. 27, n. 3, p. 412-423, 2019.

FERRARI, W.; Vaz, V. O efeito da alteração das regras no jogo de andebol na utilização do guarda redes avançado. Resumo Científico. Fortaleza, Brasil, 2018.

FERRARI, W. R.; SARMENTO, H.; VAZ, V. Match analysis in Handball: A systematic review. Montenegrin Journal of Sports Science and Medicine, v. 8, n. 2, p. 63-76, 2019.

GARCÍA, I. G. El uso táctico del golpe franco en el balonmano. E-balonmano. com: Revista de Ciencias del Deporte, v. 11, n. 1, p. 39-54, 2015.

GARGANTA, J. A análise da performance nos jogos desportivos. Revisão acerca da análise do jogo. Revista portuguesa de ciências do desporto, v. 1, n. 1, p. 57-64, 2001.

GARGANTA, J. Modelação táctica em jogos desportivos: a desejável cumplicidade entre pesquisa, treino e competição. Revista Portuguesa de Ciências do Desporto, v. 7, n. 1, p. 13, 2007.

KRAHENBÜHL, T. et al. The use of the additional field player on handball: analysis of the Rio 2016 Olympic Games. Revista Internacional de Ciencias del Deporte, v. 15, n. 57, p. 295-306, 2019.

MENEZES, R. P.; DOS REIS, H. H. B. Análise do jogo de handebol como ferramenta para compreensão técnico-tática. Motriz. Journal of Physical Education. UNESP, v. 16, n.2, p. 458-467, 2010.

MIRANDA, G. N. D. S. Análise do lançamento de saída após golo sofrido em equipas de Andebol de alto nível-Estudo com recurso à análise sequencial com equipas participantes no Campeonato de Europa da 2014. Dissertação de Mestrado apresentada à Faculdade de Desporto da Universidade do Porto, Porto, 2016.

MUSA, V. et al. Participação do goleiro-linha no handebol: Análise a partir do tempo de jogo, relação numérica, posto específico e match status. Revista Portuguesa de Ciências do Desporto, v. S1, p. 213-221, 2017.

OKAZAKI, V. H. A. et al. Ciência e tecnologia aplicada à melhoria do desempenho esportivo. Revista Mackenzie de Educação Física e Esporte, v. 11, n. 1, 2012. 


\section{BALIZA DESERTA}

PRIETO, J.; GÓMEZ, M. A.; SAMPAIO, J. Revisión bibliométrica de la producción científica en balonmano. Cuadernos de Psicología del Deporte, v. 15, n. 3, p. 145-154, 2015.

PRUDENTE, J. Análise da performance táctico-técnica no andebol de alto nível. Tese de Doutoramento apresentada à Universidade da Madeira, Funchal, 2006.

PRUDENTE, J. F. et al. Analyzing the influence of playing time and partial score on the tactical behavior in the duel 2 vs 2 in the offensive process in handball, using the polar coordinates technique. Anales de psicología, v. 33, n. 3, p. 515-529, 2017.

SECO, J. D. D. R. Actualización histórica de la evolución del juego en balonmano en el siglo XXI. Ebalonmano. com: Journal of Sports Science/Revista de Ciencias del Deporte, v. 11, n. 2, 2015.

SILVA, J. A. Modelação táctica do processo ofensivo em andebol: estudo de situações de igualdade numérica, 7 vs 7 , com recurso à análise sequencial. Tese de Doutoramento apresentada à Universidade do Porto, Porto, 2008.

SILVA, J. A.; GARGANTA, J.; JANEIRA, M. A.. Análise do comportamento de equipas de Andebol após entrada em posse de bola sem sofrer golo nas situações 7 vs 7 . Estudo do comportamento das equipas vitoriosas e derrotadas, com recurso à análise sequencial. Revista Portuguesa de Ciências do Desporto, v. 13, n. 2, 2013.

SILVA, J. A.; LEAL, L. $O$ ataque sem guarda-redes no Campeonato do Mundo de Andebol de 2017 de Seniores masculinos. Frequência e eficácia dessas ações em função da relação numérica.

Resumo Científico. Porto, Portugal, 2017.

TELES, N.; VOLOSSOVITCH, A. Influência das variáveis contextuais no desempenho das equipes nos últimos 10 minutos do jogo de handebol. Revista Brasileira de Educação Física e Esporte, v. 29, n. 2, p. 177-187, 2015.

VOLOSSOVITCH, A. Research topics in team handball. In: Performance Analysis in Team Sports. Routledge, 2016. p. 214-231. 